\title{
Identification and Influence of the External Elements on the Transmission System Operator's Responsibility Area
}

\author{
P. I. Domingues dos Santos e Abreu ${ }^{(1)}$ \\ C. Machado Ferreira ${ }^{(2)}$ \\ Department of Electrical Engineering \\ Polytechnic Institute of Coimbra/Institute of Engineering \\ IPC/ISEC and INESC Coimbra \\ Coimbra, Portugal \\ ${ }^{(1)}$ patricia.santos@isec.pt, ${ }^{(2)}$ cmacfer@ieee.org
}

\author{
Rui Pestana \\ REN, Rede Eléctrica Nacional \\ Lisboa, Portugal \\ rui.pestana@ren.pt \\ F. P. Maciel Barbosa \\ Faculdade Engenharia \& INESC TEC, Universidade do Porto \\ Porto, Portugal \\ fmb@fe.up.pt
}

\begin{abstract}
In this paper is presented a methodology to identify and evaluate the influence of the external elements on the Transmission System Operator's (TSO) responsibility area. The algorithm is based on the influence factor approach and is described for this purpose. This algorithm offer a concrete support in the determination of the observability area, which at the end remains in the responsibility of a single TSO. The influence factor is a numerical value used to quantify the greatest effect of the outage of an external network component on any internal network branch. The proposed methodology was applied to identify and to assess the influence of the external elements on the Portuguese transmission network. All simulations of the Portuguese and Spanish systems were performed using the computational software package PSS/E of Siemens/PTI. The results obtained with the proposed methodology are compared with the solutions produced by the horizontal network methodology.
\end{abstract}

Index Terms - Cross-borders Electricity Transits, Influence Factor, Responsibility and Observability Areas, Security Assessment, Transmission System Operator.

\section{INTRODUCTION}

The new paradigm of the electricity sector is critical to develop new efficient and reliable methodologies to study and analyze the security of the power networks. The TSO are confronted daily with unpredictable events in their electric power networks that may have a severe impact on the security level of the grid far exceeding all the security rules and principles used for operation and, consequently, compromising the essential service to the consumers [1]. The security assessment of electric power systems is one of the main objectives of the operation of the European Network, since it is fully interconnected. The operation of the interconnected system is based on the simple principle that each system operator is responsible for its own network and the TSO by the co-ordination of the regional network [2].

The Iberian cross-border transmission capacity may be subject to significant fluctuations in time, due to the variability of the generation level and unpredictable consumption patterns, as a result of accidental or planned outages of its components. Different scenarios of generation, consumption forecast and credible information on the prediction of system outages in each horizon are taken into account in order to evaluate the cross-border availability, avoid transmission congestion and market splitting. Consequently, if the interchange capacity is limiting the market, the Iberian market will be splitted and we will have two market prices [3].

Effective congestion management is one of the major tasks performed by the TSO and a fundamental aspect for a reliable and efficient operation of an electricity market. Each TSO must identify the relevant network areas to international flows. Such identification results in the definition of the horizontal network, which includes all network elements that are significantly affected by cross-border flows. It is also important to evaluate the influence of the external elements on the responsibility area of the TSO [3].

Under agreements between Portugal and Spain on the development of the Iberian electricity market, there has been a substantial increase in interconnection capacity between the two countries. In May 2011, the interchange capacity between the two Iberian systems was approximately $2100 \mathrm{MW}$ from Spain to Portugal and $2200 \mathrm{MW}$ in the opposite direction. It is expected that these capabilities will be reinforced until 2014, allowing to achieve a new interchange capacity of approximately of $3000 \mathrm{MW}$ which will be available in both directions [4]. This should reduce 
significantly the level of congestion that affects the interconnections between the two systems. In order to accomplish this expansion strategy, it is essential to implement new corridors:

- One line between Tavira and P. Guzman with a voltage level of $400 \mathrm{kV}$,

- One line between Vila Fria and O. Covelo with a voltage level of $400 \mathrm{kV}$.

Currently, there are nine cross-border tie-lines in the Iberian network with voltage levels from $132 \mathrm{kV}$ to $400 \mathrm{kV}$. A new tie-line between Lagoaça (Portugal) and Aldeadávila (Spain), in the Douro International area, with a voltage level of $400 \mathrm{kV}$ was recently commissioned. With this new cross-border interconnection it is essential to understand how the National Transmission Grid will be affected. It is expected that the reinforcement of electricity interconnections between the two countries improves the security and competitiveness of domestic energy supply [5].

In this paper is presented a methodology to identify and evaluate the influence of the external elements on the TSO responsibility area. The algorithm based on the influence factor approach is described for this purpose. These techniques offer a concrete support in the determination of the observability area, which at the end remains in the responsibility of a single TSO. The influence factor is a numerical value used to quantify the greatest effect of the outage of an external network component on any internal network branch. The proposed methodology will be applied to identify and to assess the influence of the external elements on the Portuguese transmission network. All simulations of the Portuguese and Spanish systems were performed using the computational software package PSS/E of Siemens/PTI. The savecases used in this study represent pictures of the real systems. The results obtained with the proposed methodology are compared with the solutions produced by the horizontal network approach, since both methodologies allow to identify the relevant electric power network of an area on a neighboring country.

\section{FormULATION OF THE PROBLEM}

For a better understanding of the proposed methodology this section is organised as follows: part A is devoted to the responsibility and observability areas description, part $\mathrm{B}$ describes the influence factor method and part $\mathrm{C}$ presents the horizontal network approach.

\section{A. Responsibility and observability areas}

The contingency list of each individual TSO is defined as the list of all internal normal and exceptional contingencies considered relevant according to the TSO's risk assessment procedure [6]. The contingency list includes also the external normal and exceptional contingencies that have to be taken into account by the security evaluation procedure due to the potential effect on an element of the TSO responsibility area. The TSO is required to simulate the $n-1$ principle, i.e., the first order contingency criterion, within its own network, which includes all lines of interconnection networks and their neighbours. This area is designated area of responsibility of the respective TSO [7].
The observability area is composed of the TSO own grid, interconnections and relevant neighbouring network, taking into account the effect of loss of related grid elements. Furthermore, the area of responsibility is constituted by own power network and interconnections, where there is the impact assessment of losses in observability area [5], [7]. In fig. 1 , it is shown the observation and responsibility areas.

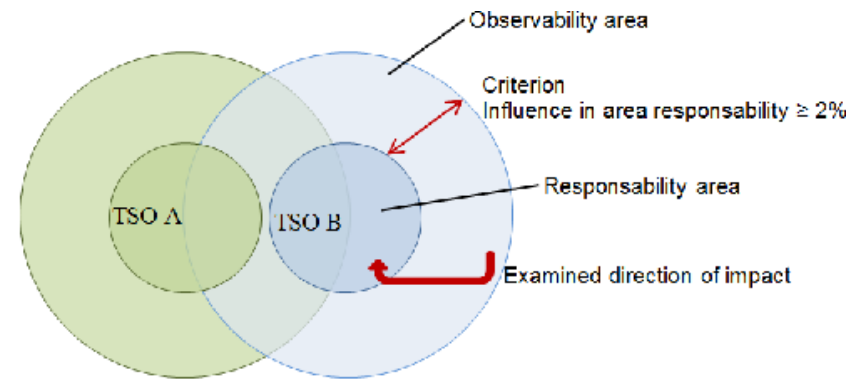

Fig. 1. First order security analysis of responsibility and observability areas.

Nowadays, each TSO is responsible for the security assessment of his own area, although a higher level of awareness and coordination among the TSO is required to improve the security of the whole interconnection. The assessment of a system security is more and more interdependent due to the increase of interconnections among systems operators. Consequently, the TSO has to take into account the influence of the surrounding grid on its responsibility area. This means that each TSO should analyse periodically, by numerical calculations, the external transmission network with influence on its responsibility area [8].

The external contingency list is the result of that analysis and includes all the components of surrounding areas that have an influence on its responsibility area higher than a certain value, named the contingency influence threshold. It is required that each TSO determine its list of external contingencies and observation list related to their area of responsibility.

\section{B. Influence factor}

The influence factor is a numerical value used to quantify the greatest effect of the outage of an external network component on any internal network branch. The worse the impact, higher the influence factor will be. Equation (1) must be applied, for each external branch $r$, assessing its influence on every branch $t$ of the responsibility area, and considering any possible outage (branch $i$ ) within the responsibility area. The influence factor of an external branch $r$ is the maximum value of this evaluation [9].

$$
\left(\frac{P_{n-1}^{t}-P_{n}^{t}}{P A T L^{t}} \cdot \frac{P A T L^{r}}{P^{r}} \cdot 100\right)
$$

where

$t \quad-$ branch of the responsibility area where the active power difference is observed

$r \quad-$ branch of the responsibility area (different from branch $t$ ) considers disconnected from the network 
$P_{n-1}^{t} \quad$ - active power through the branch $t$ with the external branch $r$ and the branch $i$ disconnected from the network

$P_{n}^{t} \quad$ - active power through the branch $t$ with the external branch $r$ connected to the network and the branch $i$ disconnected from the network

$P^{r} \quad$ - active power through the external branch $r$, when connected to the network, considering the branch $i$ disconnected from the network

$P A T L^{t}$ - permanently admissible transmission loading (PATL) of the branch $t$ (MVA)

$P A T L^{r}$ - permanently admissible transmission loading (PATL) of the external branch $r$ (MVA)

Considering a responsibility area with $k$ branches, for each external branch $r$, equation (1) must be evaluated $k^{*}(k-1)$ times in order to get the influence factor of that external branch $r$. The influence factor of an external branch $r$ on the responsibility area can be evaluated according to the following equation:

$$
I n_{r}=\max _{\forall t \forall i(i \neq t)}\left(\frac{P_{n-1}^{t}-P_{n}^{t}}{P A T L^{t}} \cdot \frac{P A T L^{r}}{P^{r}} \cdot 100\right)
$$

Equation (2) shows an approach to evaluate the influence of external elements on the responsibility area. By assessing the influence factor of an external branch to each external element, it is possible to create a ranking of the influence of out-bordering elements in order to identify the external outages that can have a higher impact on the responsibility area. Once the ranking is established, each TSO must select an appropriate contingency influence threshold to evaluate the external contingency list and an appropriate observability influence threshold value in order to evaluate the external observability list.

The observability influence threshold is a numerical limit value against which the influence factors must be assessed. It is used for the determination of the external network size to be taken into account in the security analysis models, so that the impact of the external contingency list on the responsibility area is accurately represented. If a TSO needs to increase significantly the representation of external networks in real-time, then it is advisable to consider a step-by-step approach by reducing the thresholds of the influence factors leading to a stepwise expansion of the observability area [9]. The elements to be included in the observability area are determined comparing their influencing factor with an influence threshold value [10].

\section{Horizontal network methodology}

The horizontal network of the neighboring systems is one of the important issues that Energy Management System (EMS) have to take into account in order to identify the relevant external network. The transmission lines that are significantly affected by cross-border trading comprise the so-called horizontal network [11]. For most countries, the horizontal network consists at least of the $400 \mathrm{kV}$ interconnections, transmission lines and substations. This concept can be equally applied to existing or future transmission lines [12].
The horizontal network determination is based on the variation of flows on transmission lines and transformers when adding a transit, i.e., a flow entering on a set of tie-lines and exiting through another set. Each country is studied independently. Tie-lines are modeled as the only external injections or extractions from the network of each country. It is impossible to simulate all possible transits through a network, as there are too many possible patterns and an infinite number of possible magnitudes. However, any transit through a country can be seen as a combination of several individual transits [2].

In order to find the horizontal network, the transmission lines that belonging to a given area must be clearly identified. This is accomplished by applying a standard $100 \mathrm{MW}$ flow between each couple of nodes connecting the selected country with the others. All the national lines carrying a power greater than or equal to $1 \mathrm{MW}$ are considered belonging to the horizontal network of the selected country, since it was the threshold value of the horizontal network for the Inter-TSO Compensation (ITC) rate. Formally, the procedure is base on the following criterion [2], [4]:

Criterion

$$
\text { If } \underset{l, m}{\operatorname{Max}}\left(\left|F_{e}\left(t_{l m}\right)\right|\right) \geq 1 \mathrm{MW}
$$

then $e$ is part of the horizontal network

Notations

$e \quad-$ grid element (circuit or transformer)

$t_{l m}-100 \mathrm{MW}$ the individual transit normalized between tie-line $l$ and tie-line $m$

$F_{e}\left(t_{l m}\right)$ - flow in the grid element $e$ due to the $t_{l m}$ individual transit

All transmission lines, which are usually operated, are connected in order to represent the transmission system in normal operation conditions. When there are $n \times(n-1)$ transits for each individual part only $n \times(n-1) / 2$ simulations are considered, since there are overlapping flows in the network ( $n-$ is the number of tie-lines of the country with its neighbouring countries). For each grid element, the simulations give a list of flows for all the possible individual transits. Only the absolute value of transits is retained. According to the criterion specified in (3), an element is inserted in this list when the maximum value is equal or greater than $1 \mathrm{MW}$. If the maximum value is lower than $1 \mathrm{MW}$ the element is not a part of the horizontal network, i.e., components with transit flows that are lower than the threshold value are not taken into account, since the line is not influenced by the elementary transit [4].

\section{APPLICATION EXAMPLE}

The influence factor approach and the horizontal network methodology were applied to the Iberian systems in order to identify the transmission lines of the Spanish grid that are relevant for the Portuguese electric power network in order to compare the results. The Iberian systems comprise a total of 1161 buses, 221 generators, 336 loads, 76 fixed shunts and 959 transmission lines and transformers. The network analyzed has nine interconnections between Portugal and Spain that include already the new interconnection between 
Lagoaça and Aldeadávila, in Douro International area, with a voltage level of $400 \mathrm{kV}$. These interconnections are shown in Table I [4].

TABLE I. INTERCONNECTIONS BETWEEN PORTUGAL AND SPAIN

\begin{tabular}{|c|c|c|}
\hline Portugal & Spain & Voltage $(\mathrm{kV})$ \\
\hline Alto Lindoso $(S A L)$ & Cartelle 1 $($ ECTL1) & 400 \\
\hline Alto Lindoso $(S A L)$ & Cartelle 2 $($ ECTL2) & 400 \\
\hline Lagoaça $(S L G C)$ & Aldeadávila $($ CAAE) & 400 \\
\hline Falagueira $(S F R)$ & Cedillo $(C C I E)$ & 400 \\
\hline Alqueva $(S A V)$ & Brovales $($ EBVL) & 400 \\
\hline Pocinho $(S P N)$ & Aldeadávila $1(C A A E 1)$ & 220 \\
\hline Pocinho $(S P N)$ & Aldeadávila $2(C A A E 2)$ & 220 \\
\hline Pocinho $(S P N)$ & Saucelle $(C S L E)$ & 220 \\
\hline Lindoso $(S L S)$ & Conchas $(C C H)$ & 132 \\
\hline
\end{tabular}

Fig. 2 presents the interconnections between the two Iberian networks for the $400 \mathrm{kV}$ and $220 \mathrm{kV}$ voltage levels.

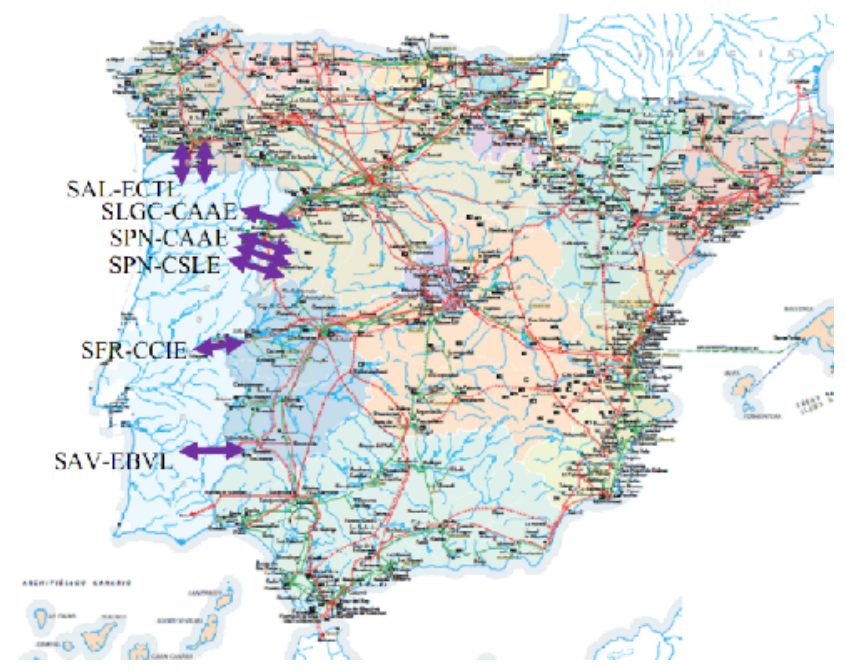

Fig. 2. Cross-border tie-lines between Portugal and Spain.

\section{RESULTS}

In this section are presented the final results produced by the two proposed methodology. In order to evaluate the impact of the external elements on the responsibility area of the Portuguese TSO was performed a power flow study using the Load Flow Solutions module of the PSS/E computer program. The Newton-Raphson method was used in all simulations and the results were stored. The initial study was carried out considering all the elements of both countries connected. A first order contingencies evaluation was performed in Spain and the cross-border power flow was monitored.

The results were analyzed and it was assumed that an element belongs to the influence factor when the elementary transit was greater than or equal to $5 \%$, otherwise it was removed, since the EMS requires this threshold value in order identify the relevant external network [13]. This procedure was repeated until all possible cases were analyzed.
In table II, are presented some of the elements of the Spanish transmission network with an influence factor equal or greater than $5 \%$.

TABLE II. ELEMENTS OF THE SPANISH NETWORK WITH AN INFLUENCE FACTOR EQUAL OR GREATER THAN 5\%

\begin{tabular}{|c|c|c|c|}
\hline Bus $i$ & $\operatorname{Bus} j$ & Voltage (kV) & $\begin{array}{c}\text { Influence } \\
\text { Factor (\%) }\end{array}$ \\
\hline CAAE & CVLE & 220 & 8.9 \\
\hline CAAE & SHJE & 400 & 17.3 \\
\hline CAAE & CVLE & 400 & 14.7 \\
\hline CAAE & SANE & 400 & 41.2 \\
\hline CAZE & EJMO & 400 & 5.2 \\
\hline CSLE & CVLE & 220 & 81.3 \\
\hline EAPR & ECON & 220 & 13.6 \\
\hline EBAL & EALV & 220 & 20.5 \\
\hline EBAL & EBVL & 400 & 28.7 \\
\hline EBEL & ECHA & 220 & 5.7 \\
\hline EBVN & EBVL & 400 & 28.4 \\
\hline ECAC & ETOJ & 220 & 65.0 \\
\hline ECAC & CORE & 220 & 65.0 \\
\hline ECMP & ELLB & 400 & 5.9 \\
\hline ECMP & EMTA & 400 & 5.4 \\
\hline ECMP & EPGR & 400 & 5.3 \\
\hline ECTL & STVE & 400 & 30.9 \\
\hline ECTL & SMVE & 400 & 96.1 \\
\hline ECTL & EPGR & 400 & 16.0 \\
\hline EEAL & EALM & 220 & 65.0 \\
\hline ELLB & EBEL & 220 & 5.3 \\
\hline EMTA & EMUD & 400 & 85.0 \\
\hline EMTA & EPGR & 400 & 77.1 \\
\hline EMUD & ETOR & 400 & 46.4 \\
\hline EPBI & ECON & 220 & 38.9 \\
\hline EPBI & EPRA & 220 & 65.0 \\
\hline EPRA & ESAG & 220 & 38.9 \\
\hline ERIC & EVLP & 220 & 5.0 \\
\hline ERIC & EZAM & 220 & 5.5 \\
\hline ESSR & EMOR & 400 & 5.1 \\
\hline ETOJ & EEAL & 220 & 65.0 \\
\hline ETOR & EZAM & 220 & 6.9 \\
\hline ETOR & EVPR & 220 & 10.8 \\
\hline ETOR & EGAL & 400 & 28.0 \\
\hline EVDC & EGUA & 400 & 28.4 \\
\hline EVLE & EHER & 400 & 77.1 \\
\hline EVLP & CVLE & 220 & 5.3 \\
\hline SANE & EJMO & 400 & 38.6 \\
\hline SANE & EMOR & 400 & 42.8 \\
\hline SANE & EVDC & 400 & 9.9 \\
\hline SGTE & EHER & 400 & 43.6 \\
\hline SGTE & EMUD & 400 & 93.5 \\
\hline SGTE & CVLE & 400 & 20.5 \\
\hline SGTE & ESSR & 400 & 26.2 \\
\hline SHJE & SANE & 400 & 35.2 \\
\hline SMVE & EPGR & 400 & 56.4 \\
\hline
\end{tabular}

The influence factor was obtained taken into account all simulations. A total of 67 branches (lines and transformers) were identified. These elements were considered as part of the external contingency list, i.e., these external components have a contingency influence factor higher than the contingency influence threshold. In this case, only the influence factors equal to or greater than $5 \%$ were taken into account. It was considered that the selected elements of the external network have an important impact on the responsibility area. 
In Fig. 3 it is shown the grid elements of Spain that have a significant impact in Portugal. The network was obtained based in all simulations and contains the elements that have been marked, i.e, those with an influence factor greater than the threshold value. The colour purple marks the transmission lines or transformers that have an influence factor equal to or greater than $5 \%$ in Spain, in accordance with the data presented in table II.

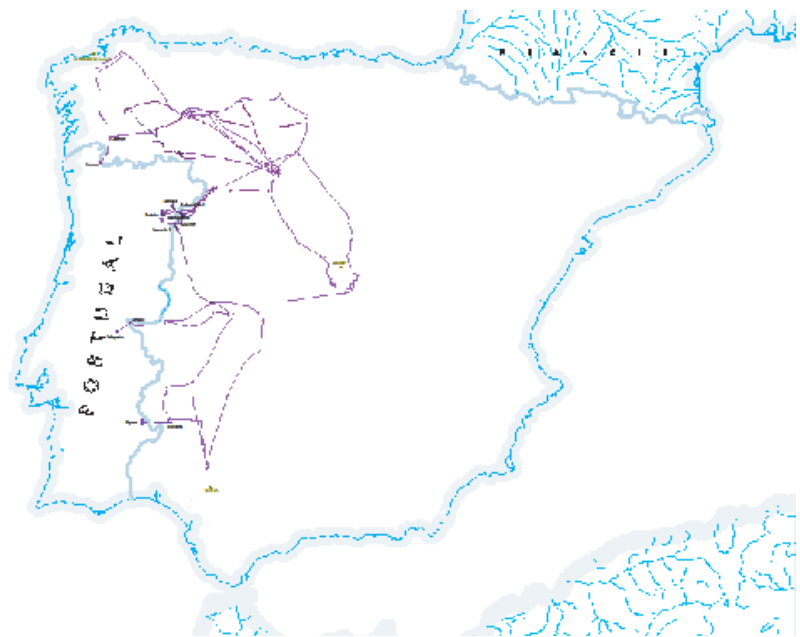

Fig. 3. Elements of network of country Spain with influence factor equal to or greater than $5 \%$.

In the north of Spain, as it is shown in Fig. 4, the lines considered as part of the external contingency extends to Puentes de García Rodríguez, near A Coruña.

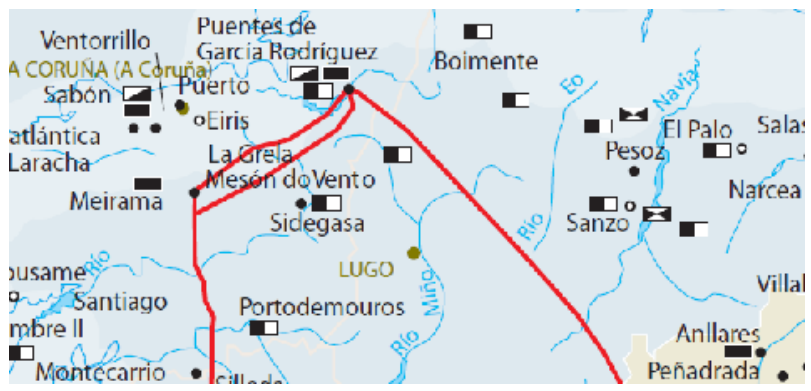

Fig. 4. Location of the further north substations.

In the east, as it is presented in Fig. 5, the relevant network extends to Madrid and includes the following nodes: Galapagar, Morata, Moraleja, Loeches, Villaviciosa and San Sebastian de los Reyes.

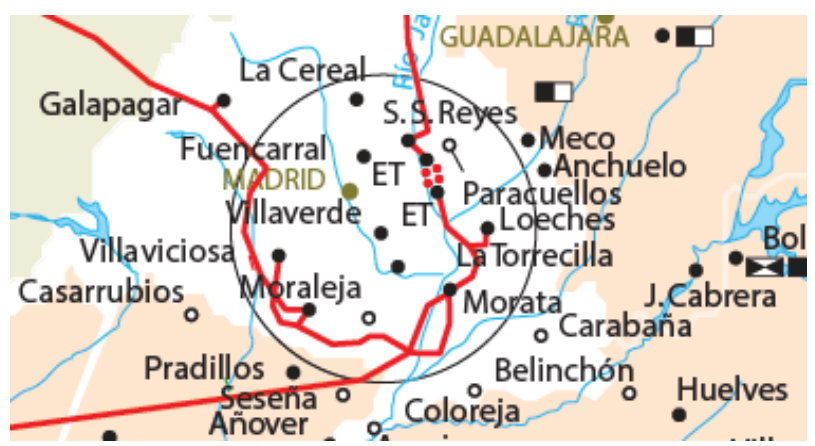

Fig. 5. Location of the further east substations.
As it is shown in Fig. 6, to the south, the network reaches Guillena substation.

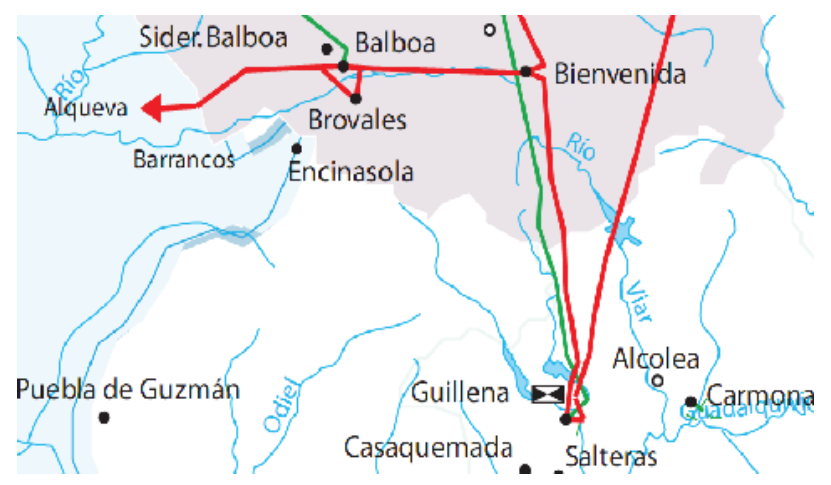

Fig. 6. Location of the further south substations.

Fig. 7 presents the relation between the influence factor threshold values and the number of external elements.

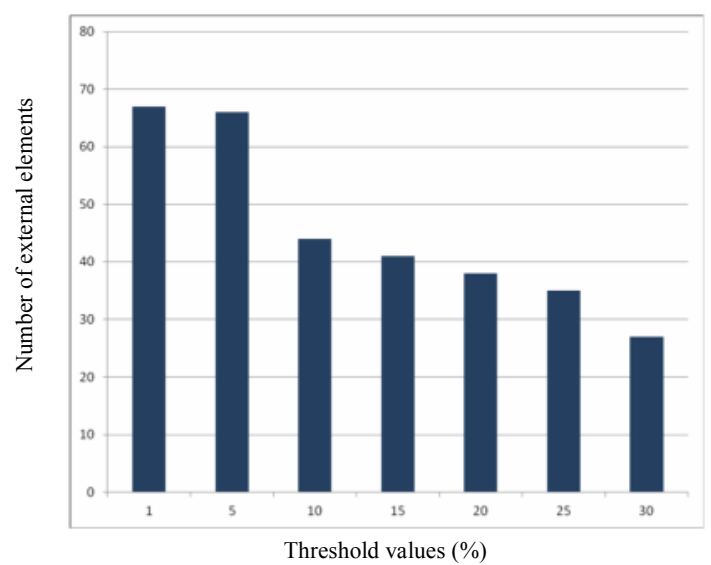

Fig. 7. Relation between the influence factor threshold values and the number of external elements.

In Fig. 8 it is presented the relevant external network of Portugal obtained combining the results of all simulations using the horizontal network approach [4], [11].

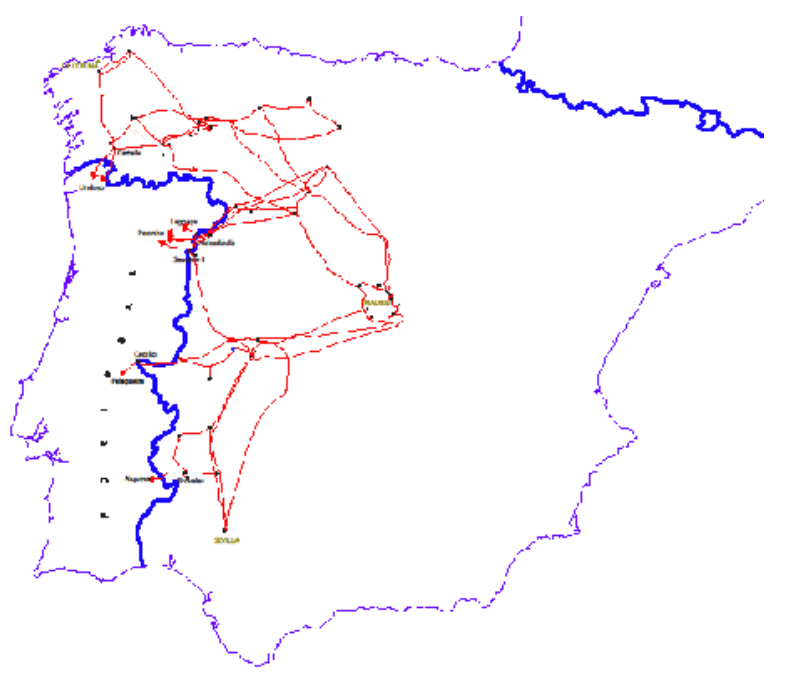

Fig 8. Relevant external network of Portugal obtained with the horizontal network approach. 
In order to identify the relevant external network of Portugal, the generators, the fixed shunts and loads have been removed from the Portuguese network, as well as all buses and transmission lines, except those that have links with the Spain. For each interconnection is used a $100 \mathrm{MW}$ generator and a load placed on other interconnection. The power flow study was performed using the DC Network Solution and Report module of the PSS/E program. The transmission lines influenced by the elementary transit are identified, i.e., the flows between any pair of nodes at the borders of the area.

The relevant external system contains the elements that have been marked, i.e., those with an elementary transit greater than the threshold value, it was assumed that an element belongs to the horizontal network when the elementary transit was greater than or equal to $5 \mathrm{MW}$, otherwise it was removed, since the EMS requires this threshold value in order identify the relevant external network [13].

Comparing figures 3 and 8 , it can be observed that there is a very close agreement between the results obtained by the influence factor method and the solutions produced by the horizontal network approach, when applied to study the Iberian systems. In both cases the same geographical areas were identified and marked as part of the relevant external network of Portugal.

\section{CONCLUSIONS}

In this paper it was presented a methodology to evaluate the impact of external elements on the responsibility area of a TSO using the influence factor method. This methodology is easy to implement, speeds up considerably the evaluation of the relevant external elements of a network for each scenario and enables an acceptable simulation time. It was shown that the proposed technique is feasible when applied in a real problem.

It was showed that the two proposed techniques are feasible when applied to the cross-border tie-lines between Portugal and Spain system. The main purpose of this study was to identify the relevant Spanish electric power network due to the new cross-border interconnection between Portugal and Spain, in the Douro International area, to understand how the National Transmission Grid will be affected. It is expected that this new tie-line will improve the security and the competitiveness of domestic energy supply.

This procedure allows to determine the influence of external elements in the area of responsibility. Thus, it was established a ranking of the elements that may have a greater impact on the area of responsibility, due to the occurrence of an external outage. The external influence area of Portugal is composed of 67 branches of Spain considering an influence factor equal or greater than $5 \%$. The number of external elements decreases sharply when the influence factor threshold values rises and consequently reducing the TSO observability area.

The majority of the branches of Spain have no influence in the external network of Portugal, since their impact factor is less than $5 \%$, as expected. Most of the buses of the external set are located in the border zone and are situated in northwest of Spain, with special relevance to the region of Galicia. The Portuguese TSO should analyze the impact of possible failures in the elements that belong to the list of external contingencies in his area of responsibility, avoiding drawbacks or problems in the event of an external disturbance.

\section{ACKNOWLEDGMENT}

The authors would like to acknowledge the support of REN, Rede Eléctrica Nacional.

\section{REFERENCES}

[1] European Parliament and Council of the European Union, "Regulation (EC) No. 714/2009 of the European parliament and of the council on conditions for access to the network for cross-border exchanges in electricity", Official Journal of the European Union, L 211/15-35. July 2009.

[2] P. I. Domingues dos Santos, Rui Pestana, C. M. Machado Ferreira and F. P. Maciel Barbosa, "Identification of the Relevant Neighbouring Electric Power Systems using the Horizontal Network Methodology", Przegląd Elektrotechniczny (Electrical Review), R. 88, NR 1a/2012, pp. 188-192.

[3] P. Torres and Rui Pestana. "Congestion management methodologies: Iberian electricity transmission grid", CIGRE/IEEE PES International Symposium, 5-7 Oct. 2005, New Orleans, Louisiana, USA.

[4] P. I. Domingues dos Santos, Rui Pestana. C. M. Machado Ferreira and F. P. Maciel Barbosa, "Identification of the Horizontal Interconnecting the Portuguese and Spanish Electric Power Systems", Proceedings of the $46^{\text {th }}$ International Universities' Power Engineering Conference, UPEC2011, $5^{\text {th }}-8^{\text {th }}$ Sep. 2011, South Westphalia University of Applied Sciences, Soest, Germany.

[5] P. I. Domingues dos Santos, J. P. Pinto e Abreu, Rui Pestana, C. Machado Ferreira and F. P. Maciel Barbosa, "Impact of External Elements on the Responsibility Area of a Transmission System Operator using the Influence Factor Method", Proceedings of the $47^{\text {th }}$ International Universities' Power Engineering Conference, UPEC2012, $4^{\text {th }}-7$ th Sep. 2012, Brunel University, London, UK.

[6] Susana Almeida, Rui Pestana and F. P. Maciel Barbosa, "Severe contingencies analysis in Portuguese transmission system", $41^{\text {st }}$ International Universities Power Engineering Conference, UPEC'06, pp.462-466, $6^{\text {th }}-8^{\text {th }}$ Sep. 2006, Northumbria University, Newcastle-Upon-Tyne, UK.

[7] ENTSO-E - European Network of Transmission Systems Operators for Electricity. UCTE Operation Handbook - Policy 3, Operational Security, March 2009.

[8] C. I. Faustino Agreira, C. M. Machado Ferreira,. J. A. Dias Pinto and F. P. Maciel Barbosa, "Application of the Rough Set Theory to the steady-state contingency classification", Proceedings of the 2005 IEEE St. Petersburg PowerTech Conference, St. Petersburg, Russia.

[9] ENTSO-E - European Network of Transmission Systems Operators for Electricity. UCTE Operation Handbook - A3: Operational Security, March 2009.

[10] D. Fabozzi, M. Glavic and L. Wehenkel. T. Van Cutsem, "Security assessment by multiple transmission system operators exchanging sensitivity and tie-line power flow information", Proceedings of the IEEE Bucharest PowerTech Conference, Bucharest, Romania, June $28^{\text {th }}-$ July $2^{\text {nd }}, 2009$.

[11] ETSO - European Transmission Systems Operators, "An Overview of Current Cross-border Congestion Management Methods in Europe", May 2006.

[12] ETSO - European Transmission Systems Operators, "The current ETSO ITC Model and possible development”, Jun. 2005.

[13] P. I. Domingues dos Santos, "Estudo da Rede Horizontal nas Interligações entre os Sistemas de Energia Eléctrica de Portugal e Espanha", M.Sc. Dissertation, Mestrado em Automação e Comunicações em Sistemas de Energia, IPC/ISEC, Coimbra, Portugal, Dec. 2010 (in Portuguese). 